\title{
Long-term health related quality of life outcomes following radical cystectomy
}

Paul T. Gellhaus ${ }^{1}$, Clint Cary ${ }^{1,2}$, Hristos Z. Kaimakliotis ${ }^{1,}$ Cynthia S. Johnson ${ }^{1}$, Michael Weiner, ${ }^{2,3}$, Michael O. Koch ${ }^{1}$, Richard Bihrle ${ }^{1}$

${ }^{1}$ Indiana University School of Medicine, Department of Urology

${ }^{2}$ Regenstrief Institute, Inc. and Indiana University Center for Health Services and Outcomes Research

${ }^{3}$ Center for Health Information and Communication, Department of Veterans Affairs, Veterans Health Administration, Health Services Research and Development Service CIN 13-416, Richard L. Roudebush VA Medical Center Indianapolis, Indiana, U.S.A.

\section{Corresponding Author: \\ Clint Cary, MD, MPH \\ Assistant Professor \\ Department of Urology \\ Indiana University School of Medicine \\ 535 N. Barnhill Drive, RT 420 \\ Indianapolis, IN 46202 \\ phone (317) 948-9272 \\ fax (317) 944-0174}

Abstract length: 248 words

Manuscript length: 2,183 words

Keywords: bladder cancer; cystectomy; urinary diversion; cancer suvivors; quality of life; outcomes

This is the author's manuscript of the article published in final edited form as:

Gellhaus, P. T., Cary, C., Kaimakliotis, H. Z., Johnson, C. S., Weiner, M., Koch, M. O., \& Bihrle, R. (2017). Long-Term Health Related Quality of Life Outcomes Following Radical Cystectomy. Urology. https://doi.org/10.1016/j.urology.2017.03.053 


\section{ACKNOWLEDGEMENT}

The views expressed in this article are those of the authors and do not necessarily represent the views of the Department of Veterans Affairs.

\section{Abstract}

\section{Objective:}

To evaluate the long-term ( $>5$ years) health-related quality of life outcomes following radical cystectomy, comparing Indiana pouch (IP), neobladder (NB), and ileal conduit (IC).

\section{Materials and Methods:}

The departmental radical cystectomy database was queried to identify patients who underwent radical cystectomy and urinary diversion for bladder cancer between 1991 and 2009 and had not died. Three hundred patients were identified and sent the validated Bladder Cancer Index (BCl) instrument.

\section{Results:}

A total of 128 (43\%) of the patients completed the survey. When adjusted for gender, age at surgery, surgeon, and time since surgery, IC and IP patients had significantly better urinary function than NB patients $(p=0.0013)$. Sexual bother was less in NB than IP $(p=0.0387)$. Among males $\geq 65$ years of age, IC patients had significantly better urinary function ( $p=0.0376$ ) than NB patients (91.6 vs. 49.4 , respectively). Among males $<65$ years of age, IC and IP patients ( 76.0 and 82.8 , respectively) had significantly better urinary function than NB patients $(50.7)(p=0.0199)$. Among females greater than 65 years, bowel bother was significantly better $(p=0.0095)$ for IC patients than IP patients (44.8 vs. 69.5 , respectively).

\section{Conclusions:}

Urinary diversion type after radical cystectomy affects health-related quality of life (HRQOL) differently in long-term survivors. Age and gender at surgery influenced HRQOL based on diversion procedure. Urinary function but not urinary bother were significantly better in IC and IP compared to NB diversions. Prospective longitudinal studies using validated HRQOL tools will further help guide preoperative diversion choice decisions between patient and surgeon.

\section{Introduction}

Approximately 74,000 new cases of bladder cancer are diagnosed annually in the United States $^{(1)}$. Radical cystectomy $(\mathrm{RC})$ with urinary diversion is performed for muscle invasive disease, high-risk nonmuscle invasive tumors such as high grade T1 with 
carcinoma in situ (CIS), early recurrence of high-grade T1 tumors, and BCG failures including BCG refractory CIS disease ${ }^{(2,3)}$. Annually, over 7,000 patients are estimated to undergo RC with diversion in the United States ${ }^{(4)}$. These patients are currently counseled through surgeon experience and the limited data available that suggest benefits of certain diversions over others. Although RC is associated with improved overall survival, it can affect health-related quality of life (HRQOL) with regard to urinary, bowel, and sexual function ${ }^{(5-8)}$.

Prior to surgery, patients are typically presented with three options for urinary diversion including continent (i.e. Indiana pouch (IP) or neobladder (NB)) and incontinent diversion (ileal conduit (IC)). Current literature has conflicting and inconclusive results regarding a superior diversion type in terms of quality of life. Each diversion type poses disparate benefits and drawbacks. The IP provides a continent option without the need for urethral utilization; however, it also is recognized to have the highest incidence of Clavien grade I-II complications ${ }^{(9)}$. NB provides daytime continence and physical normality, but it is associated with nocturnal enuresis and the potential need for urethral catheterization. ${ }^{(9)}$. As an incontinent option, the IC is associated with the lowest incidence of perioperative complications; however, it provides the least degree of lifestyle normalcy ${ }^{(9)}$. Most of the quality of life data comparing these diversion types are limited by short follow-up, which is usually within 12 months ${ }^{(10)}$. This has resulted in a paucity of literature comparing the long-term HRQOL outcomes based on diversion type. It remains unclear which diversion would provide the best HRQOL over the long term to meet the needs of individual patients.

The primary objective of this study is to evaluate the long-term HRQOL following RC, comparing IP, NB, and IC. These data could provide useful information when 
counseling patients regarding which urinary diversion may be their best option in the long term. 


\section{Methods}

After obtaining Institutional Review Board approval, the Indiana University departmental bladder cancer database was queried to identify patients who underwent RC and urinary diversion for bladder cancer between 1991 and 2009. Urinary diversions were performed as previously reported ${ }^{(11-13)}$ with vescica ileale Padovana (VIP), Studer, or Hautmann NBs. IP is a detubularized folded right colon pouch with $10 \mathrm{~cm}$ of terminal ileum used as an efferent catheterizable channel. This limb was tapered using a GIA stapler over a 12-french red rubber catheter. Continence was improved by plication stitches at the ileocecal valve. Folding the colon pouch increased the compliance and capacity. Patients were eligible to be included if they had the following: at least five years of follow-up after RC, alive based on medical records or Social Security death index data, and had a current address in the medical record. Based upon these criteria, 300 patients were identified. Surveys were mailed to patients with a stamped return envelope for survey return. Patients were also offered a secure online portal to complete the survey if they preferred. A total of $128(43 \%)$ of the patients completed the survey. The survey consisted of the Bladder Cancer Index $(\mathrm{BCl})$ instrument. $^{(14,15)}$ The $\mathrm{BCl}$ is a validated $\mathrm{HRQOL}$ instrument with disease-specific items aimed at determining urinary, bowel, and sexual domains of function and bother. The $\mathrm{BCl}$ is scored on a scale of 0 to 100 , with higher numbers representing better HRQOL outcomes. Clinical, demographic, and pathologic characteristics were extracted for each patient using our institutional database.

ANOVA was used for continuous variable comparison between groups, and chi-squared or Fisher's exact tests were used for categorical variables. ANCOVA was used to examine differences in the six $\mathrm{BCl}$ subscales among types of diversion, adjusting for 
gender, surgeon, age at surgery, and time from surgery to survey. Final pathological characteristics were not included for adjustments, since these data are not available during pre-operative patient counseling for diversion type. Since age and gender were highly associated with type of diversion, sub-analyses were performed including only males $<65$ years, males $\geq 65$ years, and females $\geq 65$ years. The decision to stratify outcomes at age 65 was based on previously published literature ${ }^{(16)}$. A sub-analysis was unable to be performed on females under 65 years because only one had a NB, and none had an IC. Sexual function in females $\geq 65$ years was unable to be evaluated due to absence of survey response to sexual function-specific questions. For all analyses with a significant diversion type effect, a pair-wise comparison was performed to determine which diversion significantly differed. When pair-wise comparisons were made, Hochberg's step-up Bonferroni adjustment for multiple comparisons was used. All statistical tests were two-sided, and SAS version 9.4 (SAS, Cary, NC, USA) was used for the analysis. 


\section{Results}

Of the 128 respondents, $102(80 \%)$ were male. The mean (SD) age at surgery was 62 years; the range was $28-82$ years. The mean (SD) time from surgery to survey was 11 years, with a minimum follow-up of 5.9 years and maximum of 23.9 years. Forty-nine patients underwent a NB. Twenty-four (50\%) underwent a VIP, $20(42 \%)$ underwent a Studer, and $4(8 \%)$ underwent a Hautmann neobladder. Both gender and age were significantly associated with type of diversion $(p<0.0001)$. Females were more likely to have IP than NB or IC $(p<0.0001)$. IC patients were significantly older than NB and IP patients $(p<0.0001)$. Unadjusted urinary function scores were highest in IP patients, $p<0.0001$. Pathological stage and lymph node involvement were not significantly different between diversion types. Patient, pathological characteristics, and unadjusted $\mathrm{BCl}$ outcomes were shown in Table $\mathbf{1 .}$

The multivariable results, adjusting for gender, age at surgery, surgeon and time from surgery to survey are presented in Table 2. There was a significant difference between types of diversion and urinary and sexual function. IC and IP patients had significantly better urinary function than NB patients $(p=0.0013)$. NB had significantly less sexual bother than IP $(p=0.0387)$.

Figure 1A, 1B, and 1C display the adjusted means based on gender and age $(<$ or $\geq 65$ years old). These statistical differences are summarized in Supplemental Table 1. Among males $\geq 65$ years of age, IC patients had significantly better urinary function than NB patients ( $p=0.0376 ; 91.6$ vs. 49.4 , respectively). Among males $<65$ years of age, IP 
patients (82.8) had significantly better urinary function than NB patients $(50.7)$ $(p=0.0199)$. Male urinary function differences by age are summarized in Figure 2.

There was not an overall significant difference in bowel function or bother between diversion types. In the sub-analysis, differences were noted among females greater than 65 years. For example, IC patients had significantly less bowel bother (91.7) than IP (69.0) patients. However, these were small sample sizes ( $n=9$ and $n=5$, respectively). 


\section{Discussion}

To our knowledge, the cohort studied provides the longest follow-up for reported HRQOL for bladder cancer survivors. We report that urinary function was better overall in IP and IC patients compared with NB patients. There were differences in outcomes based on age and gender. Older males with IC had better urinary function than older men with NB. In younger men, IP patients had significantly better urinary function than NB patients. These results were statistically significant and also likely demonstrate clinical significance, with a score difference of $25-40$ points out of $100 . \mathrm{BCl}$ urinary function questions focus primarily on urinary leakage. While leakage can occur from IP stomas or poor fitting ostomy devices for IC, these are more rare events than leakage from $\mathrm{NB}^{(6}$, 9-10). This likely accounts for the difference in urinary function score between diversions. Despite worse urinary function or leakage in NB, urinary bother was not significantly different between diversions. In the $\mathrm{BCl}$, a portion of the bother component is reflected in question $9 a$, which relates to affecting social activity. This certainly could be the most important question to consider in regards to $\mathrm{HRQOL}$ after RC. This urinary bother question evaluated how often the urinary diversion limited activity with friends. These data are depicted in Supplemental Figure 1. Regardless of diversion type, most patients answered with 'not at all' or 'a little bit' bothered $(p=0.10)$. This emphasizes the need to consider both function and bother in HRQOL analyses to provide a more complete description. For example, the NB had worse urinary function mainly due to leakage, but the bother domain suggested this was not a significant concern. Sexual bother was better in NB than IP. This could be attributed to higher rates of nerve-sparing during cystectomy with NB. Bowel bother differences were likely related to the relocation the ileocecal valve away from the gastrointestinal tract in IP patients ${ }^{(17)}$. 
Our findings differ from previous reported HRQOL studies. This may be partially explained by their shorter follow-up time ${ }^{(10,18-20)}$. A recent review of non-randomized studies using other validated HRQOL tools (SF-36, EORT QLQ-C30 and FACT BL) comparing NB to IC found that 16 studies reported no difference between the two diversions, four studies that reported NB was superior to IC, and a single study indicated that IC had better HRQOL outcomes than $\mathrm{NB}^{(21)}$. Of note, however, two of the reviewed studies also reported better HRQOL outcomes in young, fit NB patients ${ }^{(22,23)}$. This review concluded that NB was marginally better than IC, particularly in younger, fitter patients $^{(21)}$. The results of our study contrast with their findings. Specifically, we found that urinary function was better for IC comparted to NB in the overall adjusted cohort as well as both male group subgroups ( $<65$ and $\geq 65$ years old). Additionally, we found that IP had the highest urinary function in the overall adjusted cohort and younger male subgroup.

There is a paucity of literature detailing HRQOL outcomes following cutaneous continent urinary reservoir, such as the IP, following RC. One prospective study using the SF-36 instrument reported that patients with cutaneous continent urinary reservoir diversions had return of HRQOL back to baseline at one year after surgery, compared to IC scores that declined after surgery ${ }^{(24)}$. However, the SF-36 instrument does not evaluate bladder cancer-specific outcomes such as urinary function and bother, a finding that represents a significant limitation to the study. Our study demonstrates minimal long-term differences in urinary function and bother between IP and IC patients.

Several limitations should be considered. Patients were treated at a high-volume tertiary care center with a large experience with IP diversion. The results may not be generalizable to centers that are less familiar with cutaneous continent urinary reservoir 
diversions. There was likely a selection bias in this retrospective, cross-sectional design with only a $43 \%$ patient response rate. However, this response is similar to that in previous studies with shorter follow-up. ${ }^{(9,10)}$ Short-term complications have been previously reported $^{(9)}$; thus, they were not reported or statistically controlled in this analysis. In addition, short-term complications may not be relevant to this cohort that has a mean follow-up of ten years. However, in this mail-based survey we are unable to adjust to for long-term complications (i.e. incisional hernia, stones, infections, etc,) which may have biased our results. Moreover, this was a long-term survivor group of bladder cancer patients. It is unclear how these results would compare to those who died of their disease. Results may reflect a "healthy worker" effect ${ }^{(25)}$ and therefore may not be valid in patients without long-term survival. Furthermore, our cross-sectional assessment of HRQOL does not allow us to evaluate how these scores change over time. However, we are currently performing a prospective study to understand any such temporal changes. The $\mathrm{BCl}$ is a bladder cancer-specific instrument; therefore, we cannot comment on other aspects of HRQOL, such as physical and emotional function. It may be difficult to determine which diversion has superior HRQOL when function and bother are not congruent, such as our finding of the urinary function and bother. Additionally, the $\mathrm{BCl}$ has only been validated in IC and NB diversions. However, previous publications have reported its use in continent cutaneous urinary diversions ${ }^{(26,27)}$. Nevertheless, the strength of the $\mathrm{BCl}$ is its validation in patients with bladder cancer $^{(15)}$.

These limitations notwithstanding, our findings have several relevant clinical implications regarding patient counseling prior to $\mathrm{RC}$ and urinary diversion. First, males $<65$ years of age should be equally counseled about IP or IC as an alternative to NB in terms of urinary function. Second, older women with preoperative bowel issues may benefit from 
IC rather than IP. Regardless, any diversion decision should be made with a patientcentered approach with careful consideration of the individual patient's characteristics and surgeon's ability. Future studies based on preoperative baseline characteristics and HRQOL scores could help elucidate the ideal choice for a patient during preoperative counseling. We plan to study HRQOL in patients with $R C$ in a longitudinal prospective fashion.

We conclude that urinary diversion type after RC affects HRQOL differently in long-term survivors. Age and gender at surgery were associated with HRQOL based on diversion choice. Urinary function but not urinary bother were significantly better in IC and IP compared to NB diversions. Prospective longitudinal studies using validated HRQOL tools will further help guide preoperative diversion choice decisions between patient and surgeon. 


\section{REFERENCES}

1. Siegel RL, Miller KD, Jemal A. Cancer statistics, 2015. CA: a cancer journal for clinicians. 2015 Jan-Feb;65(1):5-29. PubMed PMID: 25559415.

2. Stein JP, Lieskovsky G, Cote R, Groshen S, Feng AC, Boyd S, et al. Radical cystectomy in the treatment of invasive bladder cancer: long-term results in 1,054 patients. Journal of clinical oncology: official journal of the American Society of Clinical Oncology. 2001 Feb 1;19(3):666-75. PubMed PMID: 11157016.

3. Stein JP, Skinner DG. Results with radical cystectomy for treating bladder cancer: a 'reference standard' for high-grade, invasive bladder cancer. BJU international. 2003 Jul;92(1):12-7. PubMed PMID: 12823375.

4. Leow JJ, Reese S, Trinh QD, Bellmunt J, Chung BI, Kibel AS, et al. Impact of surgeon volume on the morbidity and costs of radical cystectomy in the USA: a contemporary population-based analysis. BJU international. 2015 May;115(5):713-21. PubMed PMID: 24674655.

5. Konety $\mathrm{BR}$, Allareddy $\mathrm{V}$, Herr $\mathrm{H}$. Complications after radical cystectomy: analysis of population-based data. Urology. 2006 Jul;68(1):58-64. PubMed PMID: 16806414.

6. Gerharz EW, Mansson A, Hunt S, Skinner EC, Mansson W. Quality of life after cystectomy and urinary diversion: an evidence based analysis. The Journal of urology. 2005 Nov;174(5):1729-36. PubMed PMID: 16217273.

7. Porter MP, Penson DF. Health related quality of life after radical cystectomy and urinary diversion for bladder cancer: a systematic review and critical analysis of the literature. The Journal of urology. 2005 Apr;173(4):1318-22. PubMed PMID: 15758789. 8. Porter MP, Wei JT, Penson DF. Quality of life issues in bladder cancer patients following cystectomy and urinary diversion. The Urologic clinics of North America. 2005 May;32(2):207-16. PubMed PMID: 15862618.

9. Monn MF, Kaimakliotis HZ, Cary KC, Pedrosa JA, Flack CK, Koch MO, et al. Short-term morbidity and mortality of Indiana pouch, ileal conduit, and neobladder urinary diversion following radical cystectomy. Urologic oncology. 2014 Nov;32(8):11517. PubMed PMID: 24856979.

10. Metcalfe M, Estey E, Jacobsen NE, Voaklander D, Fairey AS. Association between urinary diversion and quality of life after radical cystectomy. The Canadian journal of urology. 2013 Feb;20(1):6626-31. PubMed PMID: 23433134.

11. Pagano F, Artibani W, Ligato P, Piazza R, Garbeglio A, Passerini G. Vescica lleale Padovana: a technique for total bladder replacement. European urology. 1990;17(2):149-54. PubMed PMID: 2311639.

12. Rowland RG, Mitchell ME, Bihrle R, Kahnoski RJ, Piser JE. Indiana continent urinary reservoir. The Journal of urology. 1987 Jun;137(6):1136-9. PubMed PMID: 3586143.

13. Smith JA, Howards SS, Preminger GM, Hinman F. Hinman's Atlas of urologic surgery. Philadelphia: Elsevier/Saunders, 2012. Available from: http://www.clinicalkey.com/dura/browse/bookChapter/3-s2.0-C20090460215.

14. Gilbert SM, Wood DP, Dunn RL, Weizer AZ, Lee CT, Montie JE, et al. Measuring health-related quality of life outcomes in bladder cancer patients using the Bladder Cancer Index (BCI). Cancer. 2007 May 1;109(9):1756-62. PubMed PMID: 17366596. 15. Gilbert SM, Dunn RL, Hollenbeck BK, Montie JE, Lee CT, Wood DP, et al. Development and validation of the Bladder Cancer Index: a comprehensive, disease specific measure of health related quality of life in patients with localized bladder cancer. The Journal of urology. 2010 May;183(5):1764-9. PubMed PMID: 20299056.

16. Imbimbo C, Mirone V, Siracusano S, Niero M, Cerruto MA, Lonardi C, et al. Quality of Life Assessment With Orthotopic lleal Neobladder Reconstruction After 
Radical Cystectomy: Results From a Prospective Italian Multicenter Observational Study. Urology. 2015 Nov;86(5):974-9. PubMed PMID: 26291562.

17. Fisch M, Wammack R, Spies F, Muller SC, Mokthar A, Ghoneim M, et al. Ileocecal valve reconstruction during continent urinary diversion. The Journal of urology. 1994 Apr;151(4):861-5. PubMed PMID: 8126811.

18. Fujisawa M, Isotani S, Gotoh A, Okada H, Arakawa S, Kamidono S. Healthrelated quality of life with orthotopic neobladder versus ileal conduit according to the SF36 survey. Urology. 2000 Jun;55(6):862-5. PubMed PMID: 10840094.

19. Erber B, Schrader M, Miller K, Schostak M, Baumunk D, Lingnau A, et al. Morbidity and Quality of Life in Bladder Cancer Patients following Cystectomy and Urinary Diversion: A Single-Institution Comparison of Ileal Conduit versus Orthotopic Neobladder. ISRN urology. 2012:342796. PubMed PMID: 22523713. Pubmed Central PMCID: 3302022.

20. Large MC, Malik R, Cohn JA, Richards KA, Ganshert C, Kunnavakkum R, et al. Prospective health-related quality of life analysis for patients undergoing radical cystectomy and urinary diversion. Urology. 2014 Oct;84(4):808-13. PubMed PMID: 25109565.

21. Ali AS, Hayes MC, Birch B, Dudderidge T, Somani BK. Health related quality of life (HRQoL) after cystectomy: comparison between orthotopic neobladder and ileal conduit diversion. European journal of surgical oncology: the journal of the European Society of Surgical Oncology and the British Association of Surgical Oncology. 2015 Mar;41(3):295-9. PubMed PMID: 24913090.

22. Philip J, Manikandan R, Venugopal S, Desouza J, Javle PM. Orthotopic neobladder versus ileal conduit urinary diversion after cystectomy--a quality-of-life based comparison. Annals of the Royal College of Surgeons of England. 2009 Oct;91(7):565-9. PubMed PMID: 19558757. Pubmed Central PMCID: 2966160.

23. Dutta SC, Chang SC, Coffey CS, Smith JA, Jr., Jack G, Cookson MS. Health related quality of life assessment after radical cystectomy: comparison of ileal conduit with continent orthotopic neobladder. The Journal of urology. 2002 Jul;168(1):164-7. PubMed PMID: 12050514.

24. Hardt J, Filipas D, Hohenfellner R, Egle UT. Quality of life in patients with bladder carcinoma after cystectomy: first results of a prospective study. Quality of life research: an international journal of quality of life aspects of treatment, care and rehabilitation. 2000 Feb;9(1):1-12. PubMed PMID: 10981202.

25. McMichael AJ. Standardized mortality ratios and the "healthy worker effect": Scratching beneath the surface. Journal of occupational medicine: official publication of the Industrial Medical Association. 1976 Mar;18(3):165-8. PubMed PMID: 1255276. 26. Longo N, Imbimbo C, Fusco F, Ficarra V, Mangiapia F, Di Lorenzo G, et al. Complications and quality of life in elderly patients with several comorbidities undergoing cutaneous ureterostomy with single stoma or ileal conduit after radical cystectomy. BJU international. 2016;118(4):521-6. PubMed PMID: 26935245.

27. Vuichoud C, Perrouin-Verbe MA, Phe V, Bitker MO, Parra J, Chartier-Kastler E. [Continent cutaneous urinary diversion after cystectomy for cancer: A reliable alternative? A monocentric retrospective study]. Progres en urologie : journal de l'Association francaise d'urologie et de la Societe francaise d'urologie. 2016;26(1112):642-50. PubMed PMID: 27717734. 
Figure 1A: Neobladder $(n=13) \dagger$ [blue], Ileal Conduit $(n=17)$ [red], Indiana Pouch $(n=15)$ [green].

†Neobladder has significantly worse urinary function than ileal conduit.

Bladder Cancer Index for males $\geq 65$ years of age at surgery, adjusting for age at surgery, surgeon, and time from surgery to survey

Males $\geq 65$ Years OId
Sexual Bother
Function
Function


Figure 1B: Neobladder ( $n=34) \ddagger$ [blue], Ileal Conduit $(n=17)$ [red], Indiana Pouch $(n=15)$ [green]. †Neobladder has significantly worse urinary function than ileal conduit.

$\ddagger$ Neobladder has significantly worse urinary function than both ileal conduit and Indiana pouch.

Bladder Cancer Index for males $<65$ years of age at surgery, adjusting for age at surgery, surgeon, and time from surgery to survey

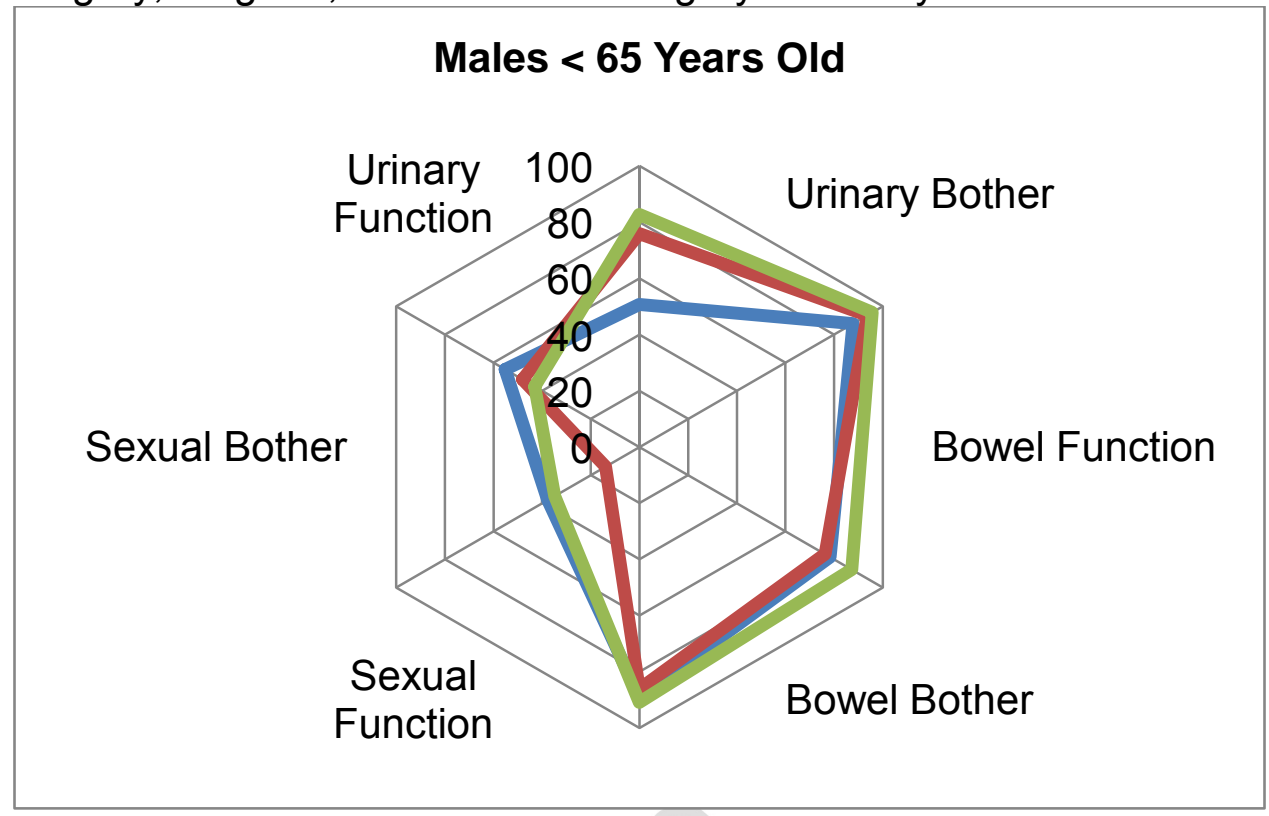


Figure 1C: lleal Conduit $(n=9)$ [blue], Indiana Pouch $(n=5)$ [red].

*Bowel bother was significantly worse in IP than IC

** Sexual function data absent due to lack of survey response to sexual functionspecific questions in female $\geq 65$ years.

Bladder Cancer Index for females $\geq 65$ years of age at surgery, adjusting for age at surgery, surgeon, and time from surgery to survey

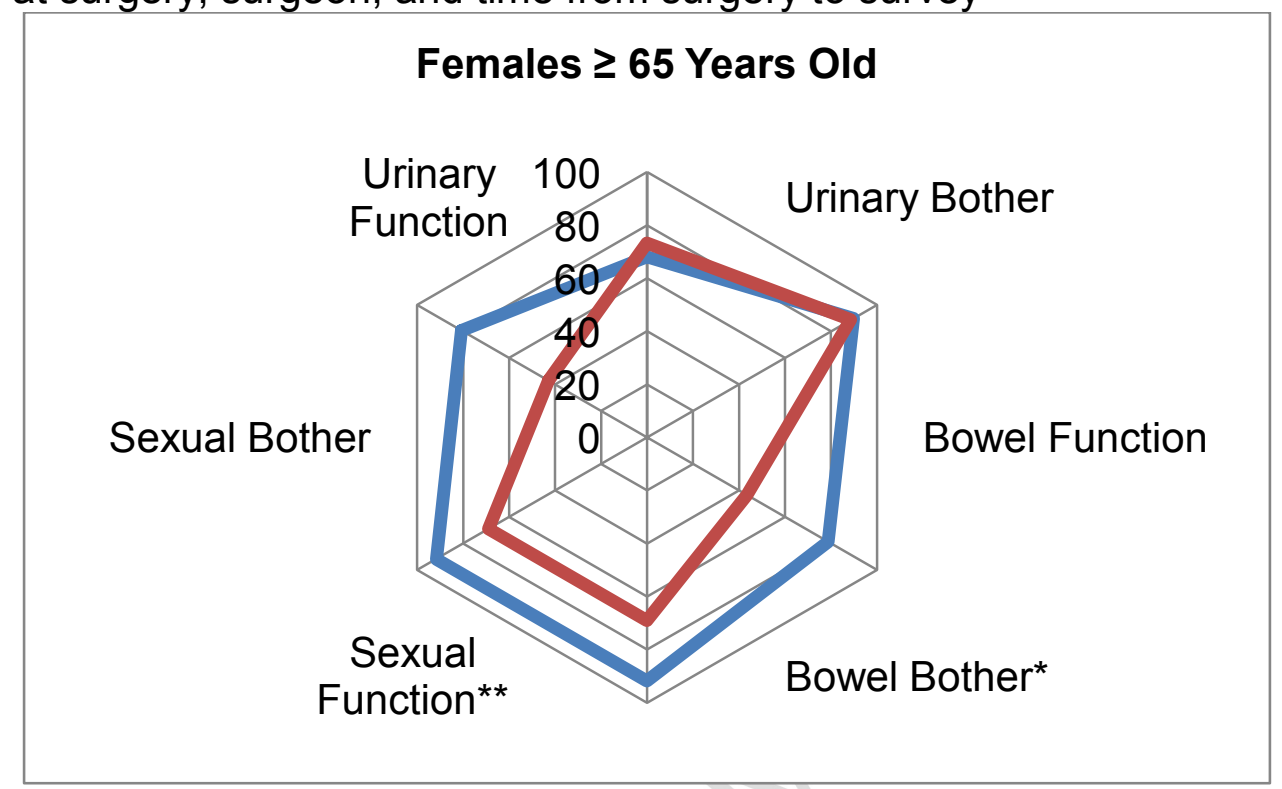


Figure 2: $<65$ years [blue], $\geq 65$ years [red]. $\dagger$ For men $\geq 65$ years, neobladder has significantly worse urinary function than ileal conduit. In men $<65$ years old, neobladder had worse urinary function than Indiana pouch and ileal conduit.

Adjusted male Bladder Cancer Index urinary function by diversion type compared by age.

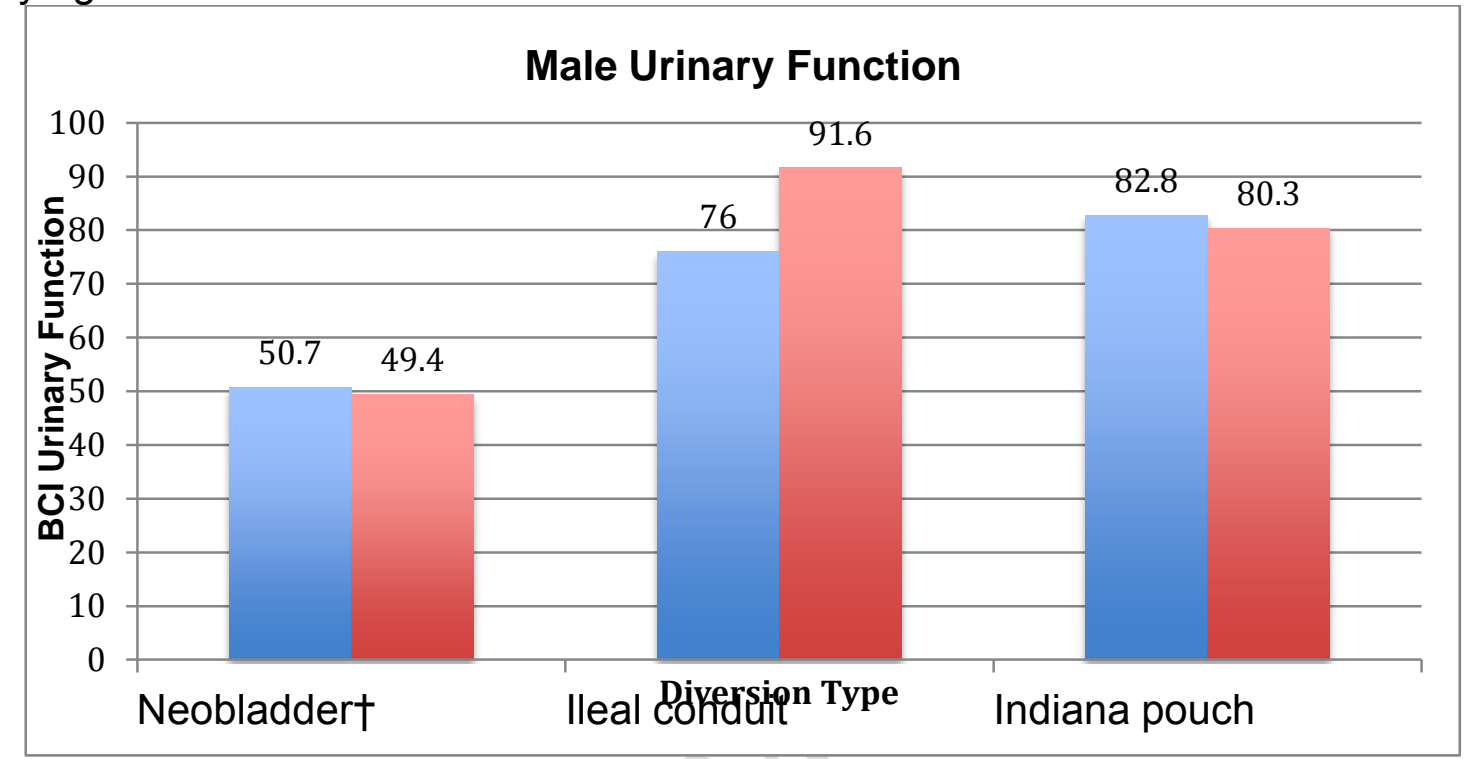

Supplemental Figure 1:

Ileal Conduit [blue], Indiana Pouch [red], Neobladder [green]. 
Table 1. Patient, Pathological characteristics, and $\mathrm{BCl}$ outcomes

\begin{tabular}{|c|c|c|c|c|}
\hline & $\begin{array}{c}\text { Neobladder } \\
(n=48)\end{array}$ & $\begin{array}{c}\text { Ileal Conduit } \\
(n=44)\end{array}$ & $\begin{array}{l}\text { Indiana Pouch } \\
(n=36)\end{array}$ & P-value \\
\hline \multicolumn{4}{|l|}{ Gender } & \multirow[t]{3}{*}{$<0.0001$} \\
\hline \multirow{2}{*}{$\begin{array}{l}\text { Male } \\
\text { Female }\end{array}$} & $47(98 \%)$ & $35(80 \%)$ & $20(56 \%)$ & \\
\hline & $1(2.1 \%)$ & $9(21 \%)$ & $16(44 \%)$ & \\
\hline \multicolumn{4}{|l|}{ Stage } & \multirow[t]{5}{*}{0.7606} \\
\hline \multirow{4}{*}{$\begin{array}{l}\leq \mathrm{pT} 1 \\
\text { pT2 } \\
\text { pT3 } \\
\text { pT4 }\end{array}$} & $30(63 \%)$ & $18(40 \%)$ & $21(14 \%)$ & \\
\hline & $9(19 \%)$ & $12(28 \%)$ & $6(17 \%)$ & \\
\hline & $7(16 \%)$ & $11(26 \%)$ & $7(19 \%)$ & \\
\hline & $2(4.2 \%)$ & $2(4.7 \%)$ & $2(5.6 \%)$ & \\
\hline \multicolumn{4}{|l|}{ Lymph node status } & \multirow[t]{3}{*}{0.9408} \\
\hline \multirow{2}{*}{$\begin{array}{l}\text { Positive } \\
\text { Negative }\end{array}$} & $7(15 \%)$ & $6(14 \%)$ & $6(17 \%)$ & \\
\hline & $41(85 \%)$ & $37(86 \%)$ & $30(83 \%)$ & \\
\hline $\begin{array}{l}\text { Age at surgery, } \\
\text { Mean (SD) (16) }\end{array}$ & $58.4(9.1)$ & $67.2(9.4)$ & $61.8(8.5)$ & $<0.0001$ \\
\hline $\begin{array}{l}\text { Years from surgery } \\
\text { to survey, Mean } \\
\text { (SD) }\end{array}$ & $10.1(3.3)$ & $10.8(5.6)$ & $12.7(5.6)$ & 0.0513 \\
\hline \multicolumn{5}{|l|}{ BCl, Mean (SD) } \\
\hline Urinary function & $50.1(30.6)$ & $79.5(26.8)$ & $81.6(25.6)$ & $<0.0001$ \\
\hline Urinary bother & $88.2(14.7)$ & $92.8(8.9)$ & $94.6(7.2)$ & 0.04 \\
\hline Bowel function & $82.6(15.3)$ & $79.9(14.7)$ & $80.0(23.4)$ & 0.74 \\
\hline Bowel bother & $90.5(11.4)$ & $89.7(10.5)$ & $84.8(13.9)$ & 0.11 \\
\hline Sexual function & $30.7(25.8)$ & $18.0(21.7)$ & $30.1(28.4)$ & 0.14 \\
\hline Sexual bother & $53.0(26.8)$ & $53.5(32.5)$ & $47.1(30.8)$ & 0.67 \\
\hline
\end{tabular}

Table 2. Analysis of covariance adjusting for gender, age at surgery, surgeon, and time from surgery to survey.

\begin{tabular}{|l|c|c|c|c|c|c|c|}
\hline & \multicolumn{2}{|c|}{ Neobladder } & \multicolumn{2}{c|}{$\begin{array}{c}\text { Ileal } \\
\text { Conduit }\end{array}$} & \multicolumn{2}{c|}{$\begin{array}{c}\text { Indiana } \\
\text { Pouch }\end{array}$} & \\
\hline Adjusted Means & Mean & SE & Mean & SE & Mean & SE & P-value \\
\hline Urinary Function & 55.3 & 7.1 & 80.4 & 6.2 & 84.4 & 5.7 & $0.0013^{*}$ \\
\hline Urinary Bother & 89.7 & 2.9 & 93.3 & 2.5 & 95.3 & 2.3 & 0.2400 \\
\hline Bowel Function & 74.1 & 4.4 & 78.0 & 3.6 & 77.3 & 3.5 & 0.7208 \\
\hline Bowel Bother & 90.5 & 3.0 & 90.4 & 2.4 & 86.3 & 2.4 & 0.3685 \\
\hline Sexual Function & 39.7 & 6.2 & 23.8 & 6.2 & 36.4 & 5.2 & 0.1017 \\
\hline Sexual Bother & 76.9 & 7.3 & 65.3 & 6.6 & 54.0 & 6.0 & $0.0387 \dagger$ \\
\hline
\end{tabular}

